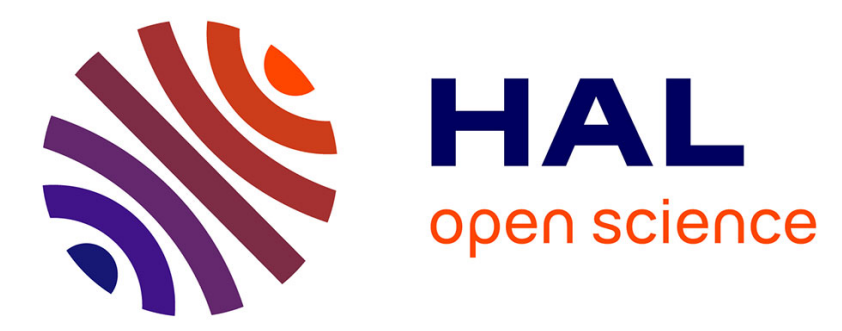

\title{
Structure of C6H12 films on graphite
}

\author{
A. Razafitianamaharavo, P. Convert, J.P. Coulomb, B. Croset, N. \\ Dupont-Pavlovsky
}

\section{To cite this version:}

A. Razafitianamaharavo, P. Convert, J.P. Coulomb, B. Croset, N. Dupont-Pavlovsky. Structure of C6H12 films on graphite. Journal de Physique, 1989, 50 (20), pp.3133-3146. 10.1051/jphys:0198900500200313300 . jpa-00211131

\section{HAL Id: jpa-00211131 https://hal.science/jpa-00211131}

Submitted on 1 Jan 1989

HAL is a multi-disciplinary open access archive for the deposit and dissemination of scientific research documents, whether they are published or not. The documents may come from teaching and research institutions in France or abroad, or from public or private research centers.
L'archive ouverte pluridisciplinaire HAL, est destinée au dépôt et à la diffusion de documents scientifiques de niveau recherche, publiés ou non, émanant des établissements d'enseignement et de recherche français ou étrangers, des laboratoires publics ou privés. 
Classification

Physics Abstracts

$61.12-61.10-68.45$

\title{
Structure of $\mathrm{C}_{6} \mathrm{H}_{12}$ films on graphite
}

\author{
A. Razafitianamaharavo $\left({ }^{1}\right)$, P. Convert $\left({ }^{2}\right)$, J. P. Coulomb $\left({ }^{3}\right)$, B. Croset $\left({ }^{4}\right)$ \\ and N. Dupont-Pavlovsky $\left({ }^{(}\right)$ \\ ( $\left.{ }^{1}\right)$ CNRS, Laboratoire Maurice Letort, BP 104, 54600 Villers les Nancy, France \\ (2) Institut Laue Langevin, 156 Centre de Tri, 38042 Grenoble Cedex, France \\ (3) CRMC2, Département de Physique, Faculté des Sciences de Luminy, Case 901, 13288 \\ Marseille Cedex 09, France \\ $\left({ }^{4}\right)$ Groupe de Physique des Solides, ENS, Paris VII, 75251 Paris Cedex 05, France
}

(Reçu le 10 avril 1989, accepté sous forme définitive le 15 juin 1989)

\begin{abstract}
Résumé. - Une étude du cyclohexane adsorbé sur graphite a été effectuée par diffraction de neutrons et de rayons X entre 77 et $260 \mathrm{~K}$. Dans le domaine de la monocouche, trois structures solides ont été observées qui sont, par ordre de densité croissante, une structure commensurable $\sqrt{7} \cdot \sqrt{7},\left(S_{1}\right)$, une structure hexagonale incommensurable $\left(S_{2}\right)$, et une structure rectangulaire centrée $\left(\mathrm{S}_{3}\right)$. La température de fusion était située à $240 \mathrm{~K}$, et un diagramme de phases proposé. Une seule couche monomoléculaire est adsorbée à $77 \mathrm{~K}$ avant la condensation tridimensionnelle, alors que deux couches sont adsorbées à $233 \mathrm{~K}$. La formation de la seconde couche fait intervenir une transition du premier ordre d'une monocouche hexagonale $\left(\mathrm{S}_{2}\right)$ en une bicouche rectangulaire centrée $\left(S_{3}\right)$.
\end{abstract}

\begin{abstract}
An X-ray and neutron scattering study of $\mathrm{C}_{6} \mathrm{H}_{12}$ adsorbed on graphite has been performed from 77 to $260 \mathrm{~K}$. In the monolayer range, three solids have been observed ; they exhibit, in order of increasing density, a commensurate $\sqrt{7} \cdot \sqrt{7}$ structure $\left(S_{1}\right)$, an incommensurate hexagonal structure $\left(S_{2}\right)$, and a centered rectangular structure $\left(S_{3}\right)$. The melting temperature has been located at $240 \mathrm{~K}$, and a tentative phase diagram has been proposed. Only one layer is adsorbed at $77 \mathrm{~K}$ before $3 \mathrm{D}$ condensation, whereas two layers are adsorbed at $233 \mathrm{~K}$. The completion of the second layer occurs according to a first order transition process from a hexagonal monolayer $\left(S_{2}\right)$ to a centered rectangular bilayer $\left(S_{3}\right)$.
\end{abstract}

\section{Introduction.}

Rare gas adsorption on graphite has given rise to numerous thermodynamical and structural investigations. In the case of more complex molecules, which were then. studied, $2 \mathrm{D}$ solid phases with no equivalent plane in the bulk were found, some of them being commensurate [2-4]. Such structures could be expected for cyclohexane $\left(\mathrm{C}_{6} \mathrm{H}_{12}\right)$, owing to its molecule non globular shape and large size. The thermodynamical properties of $\mathrm{C}_{6} \mathrm{H}_{12}$ films physisorbed on (0001) graphite have been studied for the last years by adsorption isotherm measurements [58]. In the most developed and recent investigation [8] a set of isotherms is presented in the 
203-293 K temperature range. The isotherms exhibit two steps, corresponding to the adsorption of two monolayers before reaching the saturating vapour pressure. From the temperature dependence of the second step pressure, the second layer was shown to appear at $145 \mathrm{~K}$. Below this temperature, only one monolayer was assumed to be adsorbed. The first layer critical temperature was estimated to be $237 \pm 1 \mathrm{~K}$. The completion of the first monolayer was located on the isotherm at the beginning of the plateau between the two steps, the adsorbed molecule cross being section $36.75 \AA^{2}$ at this point. The second step height is larger than that of the first : the ratio between the amounts respectively adsorbed at the first and the second layer completion is 2.27. From these results, and on the basis of thermodynamical considerations, the author concluded that the first isotherm step is representative of a first order gas-liquid transition, the monolayer solidification occurring in the plateau. This conclusion is grounded on the difference in adsorbed amounts at the beginning and at the end of the plateau between the two isotherm steps (about $20 \%$ ). The second step is assumed to represent the second monolayer adsorption, according to a first order gas-solid transition process.

In spite of these assumptions, no information about the structure of $\mathrm{C}_{6} \mathrm{H}_{12}$ physisorbed films was available until now. In this paper we report a structural investigation of these films by neutron and $\mathrm{X}$-ray diffraction, leading to a tentative phase diagram with three different solids $\mathrm{S}_{1}, \mathrm{~S}_{2}$ and $\mathrm{S}_{3} . \mathrm{S}_{1}$ is commensurate with a $\sqrt{7} \cdot \sqrt{7}$ structure $; \mathrm{S}_{2}$ is hexagonal incommensurate and $S_{3}$ is centered rectangular.

\section{Sample characteristics and preparation}

The neutron diffraction experiments were carried out at the Laue Langevin Institute (Grenoble, France) on the two axis D1B spectrometer, equipped with a multidetector. Two series of measurements were performed. The incident beam wavelength was $2.517 \AA$ for the first one, and $2.525 \AA$ for the second.

The X-ray diffraction experiments were performed with a $1200 \mathrm{~W}$ generator producing the $\mathrm{CuK} \alpha$ radiation (wavelength $1.5418 \AA$ ) and a position sensitive detector [3].

2.1 Substrate. - The substrate was Papyex, manufactured by the firm « Le Carbone Lorraine ». It is a compressed exfoliated graphite with large specific area and a preferential orientation of the six-fold axis.

Two samples with different densities were used. The denser one is more suitable for scattering experiments on adsorbed monolayers, and has been used in numerous studies [2, 3 , 9-12]. It is compressed to $1.1 \mathrm{~g} . \mathrm{cm}^{-3}$, having a surface area estimated to be $20 \mathrm{~m}^{2} \cdot \mathrm{g}^{-1}$ and a mosaic spread of $38^{\circ}$ (full width at half maximum [10]). X-ray scattering and one of the neutron scattering experiments were carried out with it. But compression of exfoliated graphite results in a decrease of the surface uniformity and in an increase of capillary condensation phenomena during adsorption, especially when more than one monolayer is adsorbed [10-13]. That is why part of the neutron scattering experiments were performed with a less compressed Papyex, whose density was $0.1 \mathrm{~g} . \mathrm{cm}^{-3}$, specific area $40 \mathrm{~m}^{2} \cdot \mathrm{g}^{-1}$ and mosaic spread $74^{\circ}[10]$. Under these conditions, a measurable signal of the adsorbed film could still be obtained, and the adsorptive properties of the graphite surface were less altered by compression than for the $1.1 \mathrm{~g} . \mathrm{cm}^{-3}$ density Papyex.

For X-ray as well as for neutron studies, the sample was a stack of Papyex disks arranged parallel to the scattering plane. Details of the experimental procedure are given elsewhere $[2,3,10]$. 
2.2 Adsorbate. - The temperatures of three dimensional (3D) cyclohexane triple and critical points are :

$$
T_{\mathrm{t}}(3 \mathrm{D})=279.7 \mathrm{~K} \quad T_{\mathrm{c}}(3 \mathrm{D})=554 \mathrm{~K}
$$

The $\mathrm{C}_{6} \mathrm{H}_{12}$ molecule has a predominant stable configuration, the chair form, with a carboncarbon distance of $1.517 \AA$ and a carbon-hydrogen distance of $1.084 \AA[14,15]$.

Three crystalline forms of cyclohexane are known $[16,17]$ :

- solid $\mathrm{I}$ is stable between 279.8 and $186 \mathrm{~K}$. It is a plastic phase with a face centered cubic cell ; $a=8.61 \AA$ at $195 \mathrm{~K} ; Z=4$; the space group is $\mathrm{fm} 3 \mathrm{~m}$; the non-extinction rules are :

$$
\begin{array}{ll}
h k \ell & h+k, k+\ell, \ell+h=2 n \\
h h \ell & h+\ell=2 n \\
0 k \ell & k, \ell=2 n
\end{array}
$$

- solid II is stable below $186 \mathrm{~K}$. At $115 \mathrm{~K}$ crystal data are : monoclinic cell ; $a=11.23 \AA, b=6.44 \AA ; c=8.20 \AA ; \beta=108.83^{\circ} ; Z=4$; space group probably $\mathrm{C} 2 / \mathrm{c}$; non extinction rules :

$$
\begin{array}{ll}
h k \ell & h+k=2 n \\
h 0 \ell & l=2 n
\end{array}
$$

- solid III is a metastable phase obtained by quenching the liquid or solid I at $77 \mathrm{~K}$. Incomplete quenching of solid I leads to a mixture of solids II and III. Annealing of solid III at temperatures between 120 and $186 \mathrm{~K}$ irreversibly gives solid II. The solid III structure is not elucidated.

$\mathrm{C}_{6} \mathrm{H}_{12}$ was a Merck product of $99.7 \%$ purity. It was purified by pumping on the condensed phase at $193 \mathrm{~K}$ inside the introduction system. In order to enhance the coherent neutron scattering cross-section of the film, deuterated cyclohexane $\left(C_{6} D_{12}\right)$ delivered by the C.E.A. (Saclay, France) was used. $\mathrm{C}_{6} \mathrm{D}_{12}$ was kept under argon and transferred under vacuum into the introduction system.

2.2 ADSORPTION PROCEDURE. - For all experiments, the gas was introduced in contact with the sample at $233 \mathrm{~K}$, so as to control the adsorption equilibrium by pressure measurements. Lower temperatures were then slowly reached $\left(0.5^{\circ} . \mathrm{min}^{-1}\right.$ cooling) to avoid gas condensation on the cell walls. Figure 1 shows a schematic drawing of an adsorption isotherm at $233 \mathrm{~K}$, in

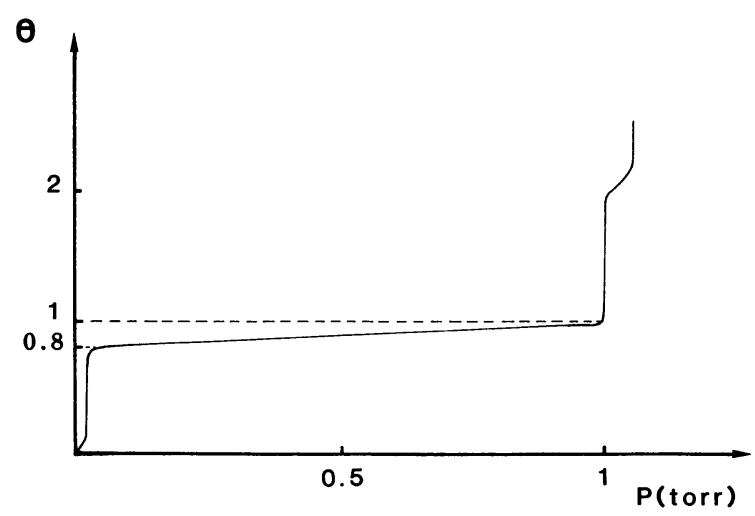

Fig. 1. - Schematic drawing of an adsorption isotherm of cyclohexane on graphite at $233 \mathrm{~K}, \theta$ : fractional coverage ; $P$ : equilibrium pressure. 
order to define the different cyclohexane coverages which have been studied. The completion of one monolayer is located at the end of the plateau between the two steps. From the slope of this plateau, it can then be deduced that its beginning corresponds to 0.8 monolayer.

\section{Results.}

3.1 NEUTRON SCATTERING STUDY OF $\mathrm{C}_{6} \mathrm{H}_{12}$ ADSORPTION IN THE MONOLAYER AND SUBMONOLAYER REGIME. - Figure 2 shows diffraction patterns obtained at 233 and $77 \mathrm{~K}$ respectively for a 0.9 monolayer $\mathrm{C}_{6} \mathrm{D}_{12}$ film adsorbed on 1.1 density Papyex. The scattering from the substrate has been subtracted. Three Bragg peaks can be distinguished in both difference spectra, the most intense of which clearly exhibits the sawtooth profile characteristic of diffraction from a 2D polycrystal. The fourth peak, observed at $Q=2.21 \AA^{-1}$ on the $77 \mathrm{~K}$ spectrum is likely to be due to a bad subtraction of the (110) aluminium peak arising from the diffraction cell. The positions of the three Bragg peaks observed on both spectra are those of a hexagonal structure of parameter $6.35 \AA$, which is incommensurate with respect to the substrate.

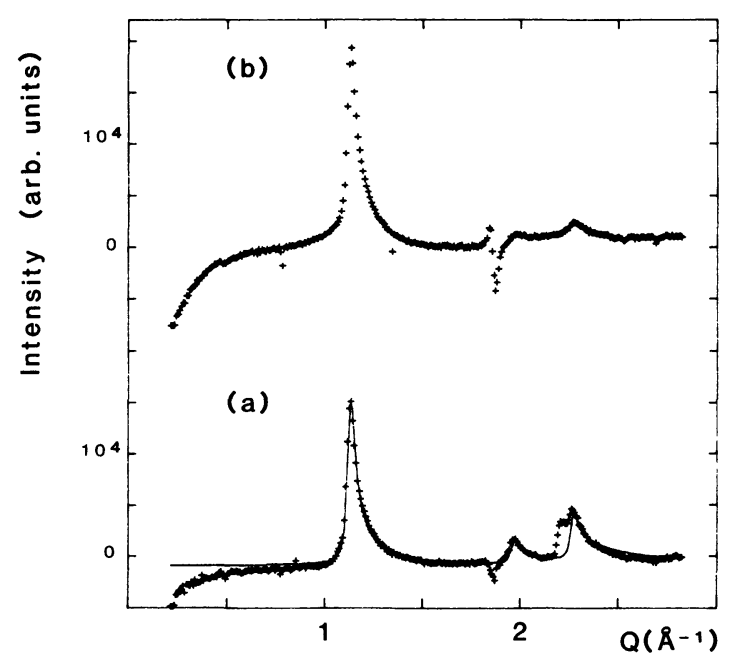

Fig. 2. - Neutron diffraction spectra of 0.9 monolayer cyclohexane films adsorbed on 1.1 density Papyex. (a) : $77 \mathrm{~K}$; (b) : $233 \mathrm{~K}$. The smooth curve is the calculated diffraction profile according to the model of Ruland and Tompa.

The relative intensities of the Bragg reflections in the $233 \mathrm{~K}$ spectrum, corrected from the Lorenz factor, are $100,7,18$. They are in good agreement with those calculated from the structure factor of a freely rotating $\mathrm{C}_{6} \mathrm{H}_{12}$ molecule $(100,8,13)$.

This model could not be applied to the $77 \mathrm{~K}$ spectrum for which the relative intensities of the same Bragg peaks are 100, 23 and 62. The experimental peaks were then fitted with those calculated by means of the model of Ruland and Tompa $[18,19]$ for a fixed position of the $\mathrm{C}_{6} \mathrm{H}_{12}$ molecule. The Debye Waller factor was set equal to unity, the three fitting parameters being the three Euler angles $(\psi, \phi$ and $\theta)$ which determine the orientation of the molecule, 
represented in figure 3 . These angles were systematically varied to find the best agreement between calculated and observed Bragg profiles. The best fit, obtained for $\psi=133^{\circ} \pm 2$, $\phi=-148^{\circ} \pm 2$ and $\theta=-16^{\circ} \pm 2$, is shown in figure 2 . Whereas several orientations give the good relative intensities of the peaks, this is the only one which leads to a profile close to the experimental spectrum. This is due to the dependence of the structure factor on $q_{z}$, to which each line profile is very sensitive $[11,20]$. The spectra obtained on 0.1 density Papyex under the same conditions of coverage and temperature are quite similar (Figs. 5a and $8 \mathrm{a})$.

The spectrum obtained at $200 \mathrm{~K}$ and 0.7 layer coverage is very similar in shape to that of the 0.9 layer, $233 \mathrm{~K}$, except that the positions of the three Bragg peaks are those of a hexagonal structure with $6.51 \AA$ parameter, instead of $6.35 \AA$ previously determined, and correspond to a commensurate $\sqrt{7} \cdot \sqrt{7}$ solid. This structure has already been observed for several adsorbates on graphite, among which benzene $[21,22,23]$ whose molecular shape is relatively close to that of $\mathrm{C}_{6} \mathrm{H}_{12}$. The unit cell area is then $36.7 \AA^{2}$. This value is in very good agreement with the molecular cross-section estimated from volumetric measurements $\left(36.7 \AA^{2},[8]\right)$ at the beginning of the plateau between the two isotherm steps $(0.8$ monolayer adsorbed with our conventions).

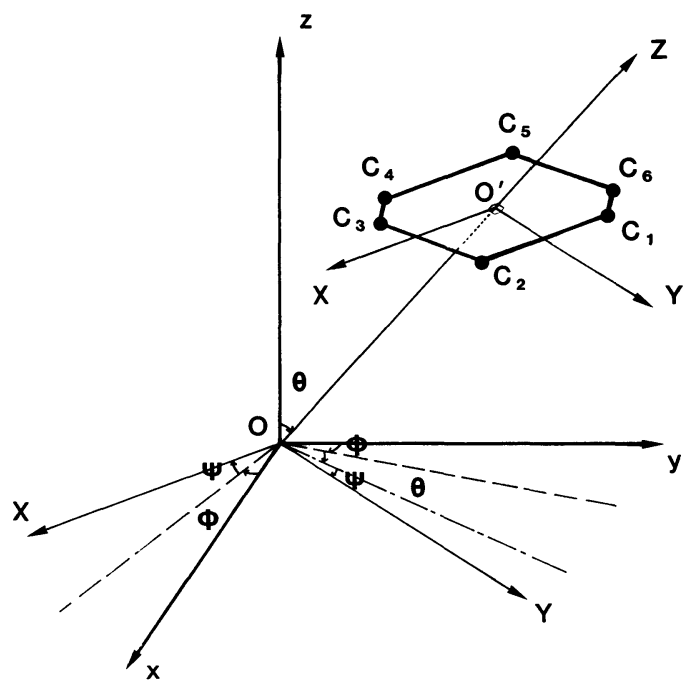

Fig. 3. - Schematic drawing of the cyclohexane molecule in the chair-form configuration, $\phi, \psi$ and $\theta$ are the Euler angles.

Figure 4 shows the changes in shape of the (10) Bragg peak at 0.7 monolayer coverage with temperature between 200 and $260 \mathrm{~K}$. From the broadening of the peak with increasing temperature, melting may be located at $240 \pm 5 \mathrm{~K}$, which is very close to the $2 \mathrm{D}$ critical temperature $(237.5 \mathrm{~K})$ previously determined [8]. This observation suggests the existence of an incipient triple point for the cyclohexane monolayer.

In conclusion to these first results, $\mathrm{C}_{6} \mathrm{H}_{12}$ adsorbed on graphite up to 0.9 monolayer was shown to form a solid with hexagonal structure whose parameter depends on the film density. The lowest density is that of a commensurate $\sqrt{7} \cdot \sqrt{7}$ solid, which forms according to a first order transition (first step on the isotherm) and whose melting temperature is $240 \mathrm{~K}$. 


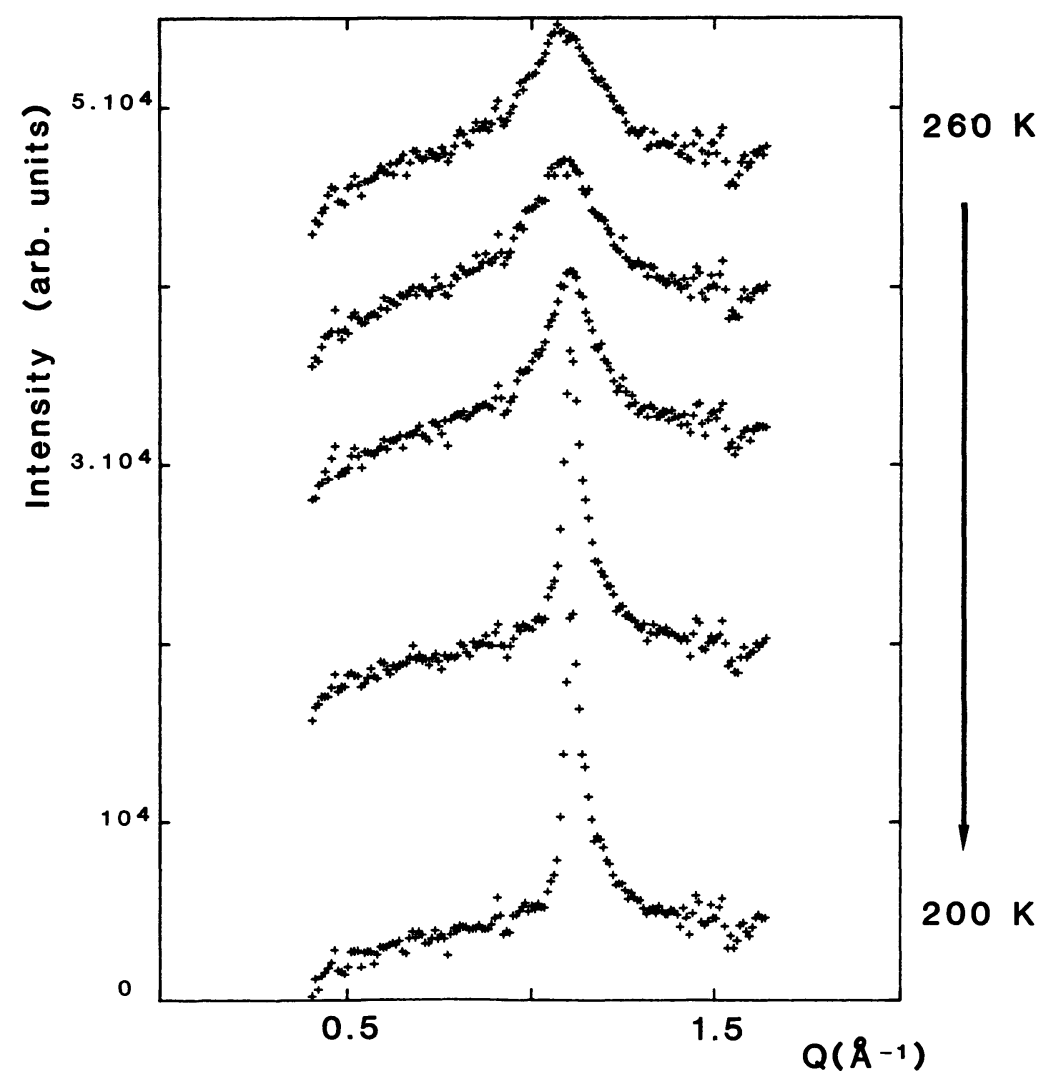

Fig. 4. - (10) diffraction profiles of 0.7 layer cyclohexane film adsorbed on 1.1 density Papyex. Dependence on temperature.

3.2 NEUTRON SCATTERING STUDY OF $\mathrm{C}_{6} \mathrm{H}_{12}$ ADSORPTION FOR COVERAGES HIGHER THAN ONE MONOLAYER. - Higher cyclohexane coverages have been studied on 0.1 density Papyex because, as it has already been emphasized, capillary condensation occurring during adsorption is less significant than on 1.1 density Papyex.

The first reported results were carried out at $77 \mathrm{~K}$, the thermodynamical study conclusions being that only one $\mathrm{C}_{6} \mathrm{H}_{12}$ monolayer can be adsorbed on graphite at this temperature $[7,8]$. Figure 5 shows diffraction spectra measured when $\mathrm{C}_{6} \mathrm{H}_{12}$ amounts equivalent to 1.3 and 2 monolayers respectively were introduced in contact with the substrate. They are different indeed from that of the 0.9 layer, and exhibit at least eight new Bragg peaks. Moreover, the relative intensities of two peaks, whose position is marked by an arrow in figure 5, clearly increase with increasing $\mathrm{C}_{6} \mathrm{H}_{12}$ amount, which could be assigned to $3 \mathrm{D}$ condensation. These results would then corroborate the previous assumption $[7,8]$ according to which only one monolayer can be adsorbed at $77 \mathrm{~K}$.

In order to determine more accurately what part of these spectra can be assigned to 3D $\mathrm{C}_{6} \mathrm{H}_{12}$ crystallites, an amount equivalent to $15 \mathrm{C}_{6} \mathrm{H}_{12}$ layers was introduced in contact with graphite. The resulting spectrum is presented in figure 6 , and is mostly $3 \mathrm{D}$, as can be seen from the symmetrical shape of the Bragg peaks. The positions of all the Bragg peaks of the previously elucidated monoclinic structure $[16,17]$ are found in the explored angular domain. Some other peaks, marked by an arrow in figure 6 , are also observed. But, as has already 


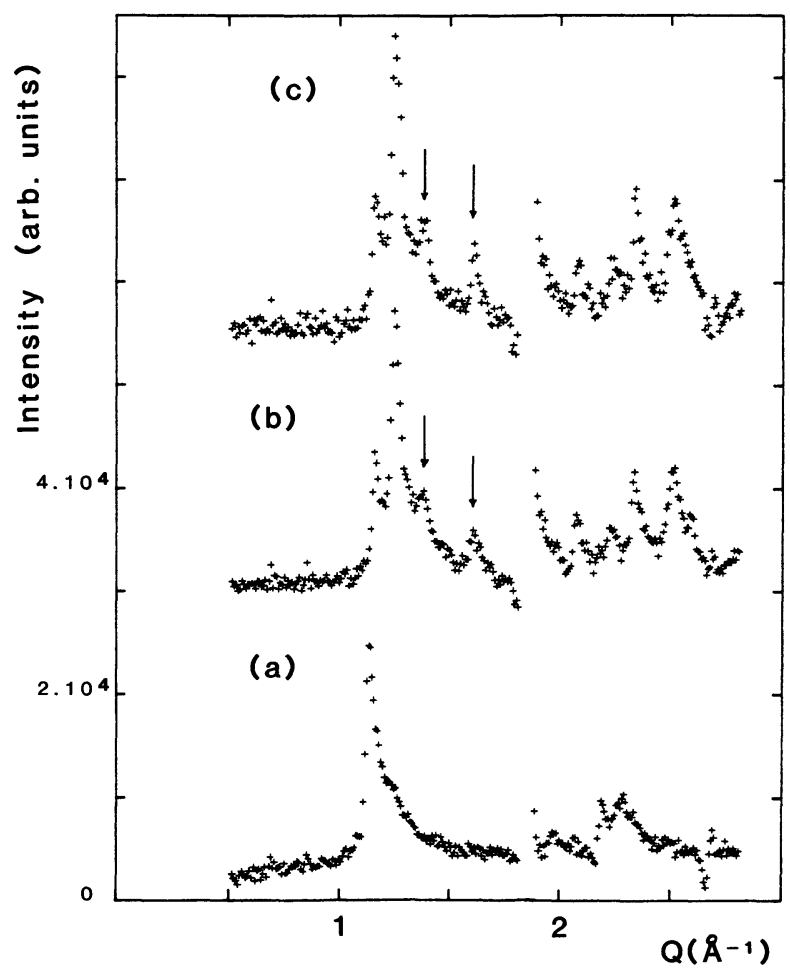

Fig. 5. - Neutron diffraction profiles of cyclohexane films adsorbed on 0.1 density Papyex at $77 \mathrm{~K}$ : (a) : 0.9 layer ; (b) : 1.3 layer ; (c) : 2 layers. Peaks marked by an arrow clearly increase with increasing coverage.

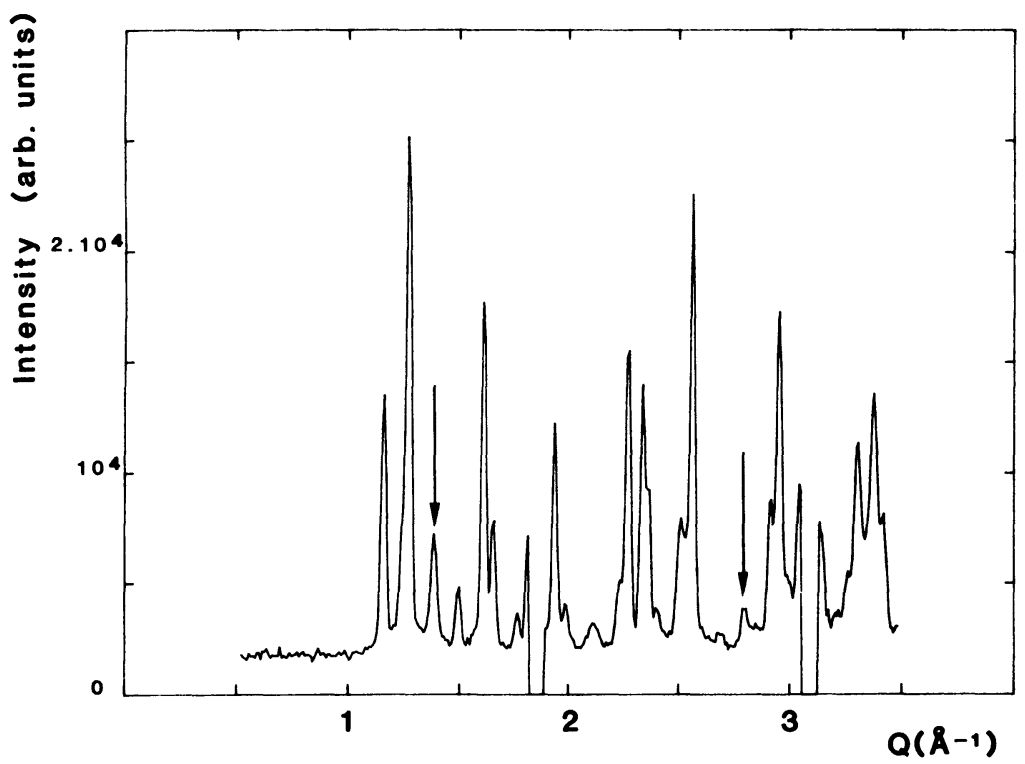

Fig. 6. - Neutron diffraction profile of 3D cyclohexane at $77 \mathrm{~K}$. Bragg peaks marked by an arrow cannot be assigned to the monoclinic phase II. They probably originate from the metastable cyclohexane phase III. 
been emphasized, incomplete quenching at $77 \mathrm{~K}$ of the high temperature $(T>186 \mathrm{~K}) 3 \mathrm{D}$ phase results in a mixture of the monoclinic phase and a metastable phase, whose structure is not yet elucidated [16, 17]. As $\mathrm{C}_{6} \mathrm{H}_{12}$ was introduced at $233 \mathrm{~K}$ and then cooled from 233 to $77 \mathrm{~K}$, we think that these extra peaks originate in the metastable structure.

Coming back to the diffraction patterns shown in figures $5 b$ and $5 c$, as could be expected, the Bragg peaks whose relative intensity increases with increasing $\mathrm{C}_{6} \mathrm{H}_{12}$ amount in contact with graphite are also observed in the $3 \mathrm{D}$ spectrum shown in figure 6 . But the positions of the other Bragg peaks are also either the same or very close to those observed in the 3D spectrum. We tried to suppress the $3 \mathrm{D}$ contributions in figures $5 \mathrm{~b}$ and $5 \mathrm{c}$ by subtracting from these patterns the figure $63 \mathrm{D}$ spectrum multiplied by the ratio of measured intensities of the typically 3D Bragg peak at $Q=1.61 \AA^{-1}$ respectively in figure 6 and in figures $5 \mathrm{~b}$ and 5c patterns. The measured values of these ratios are very close to those calculated, assuming that the $3 \mathrm{D}$ contributions in figures $5 \mathrm{~b}$ and $5 \mathrm{c}$ correspond to $\mathrm{C}_{6} \mathrm{H}_{12}$ amounts equivalent to 0.3 and 1 layer respectively in accordance with the assumption that only one layer is adsorbed at $77 \mathrm{~K}$. Results are shown in figure 7. The two patterns initially corresponding to the 1.3 and 2 layer coverages are very similar in shape and intensity. Six Bragg peaks can be distinguished in both spectra, whose positions correspond to a centered rectangular structure with the unit cell parameters $a=5.63 \AA, b=6.06 \AA$ and $\gamma=117.65^{\circ}$. The unit cell surface area is then $30.2 \AA^{2}$, instead of $36.7 \AA^{2}$ for the $\sqrt{7} \cdot \sqrt{7}$ commensurate structure. Such a decrease in the surface area may be assigned to a change in the molecule tilting with respect to the graphite surface with increasing $\mathrm{C}_{6} \mathrm{H}_{12}$ coverage up to one monolayer. We did not find a satisfactory fit of the diffraction profiles shown in figure 7 with that calculated according to the model of Ruland and Tompa, whatever the orientation of the molecule. This discrepancy might be due to an anisotropic Debye-Waller effect ; but a calculation taking this effect into account would involve too many parameters for the fit to keep a physical significance.

The same $\mathrm{C}_{6} \mathrm{H}_{12}$ coverages have also been studied at $233 \mathrm{~K}$. At this temperature, it has been established from adsorption isotherm measurements that two $\mathrm{C}_{6} \mathrm{H}_{12}$ layers can be adsorbed on

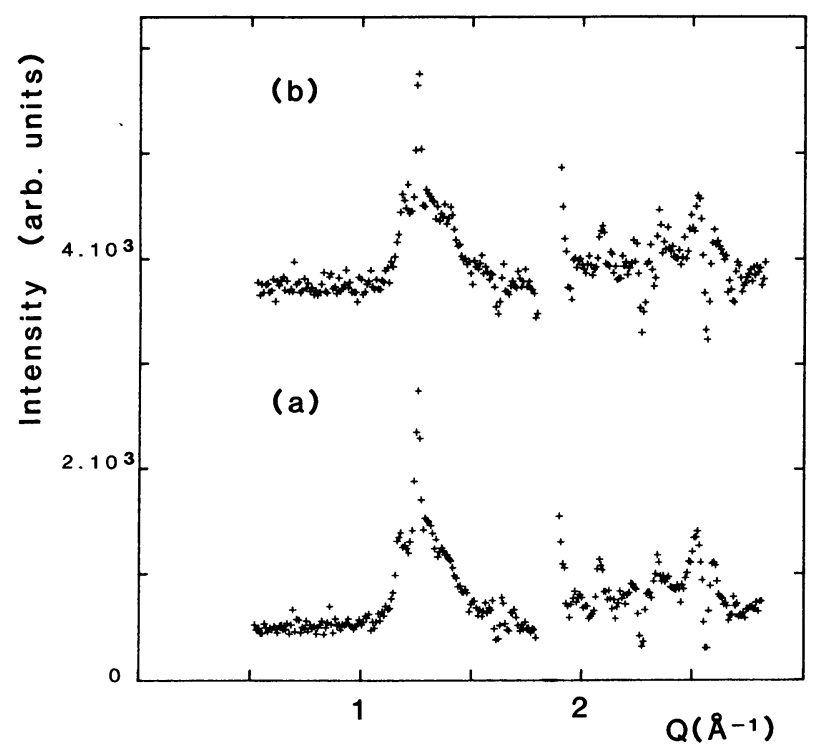

Fig. 7. - Cyclohexane adsorbed on Papyex 0.1 at $77 \mathrm{~K}$. Scattering profiles obtained by subtracting the 3D contribution to the 1.3 layer film (a) and 2 layers film (b) spectra. 


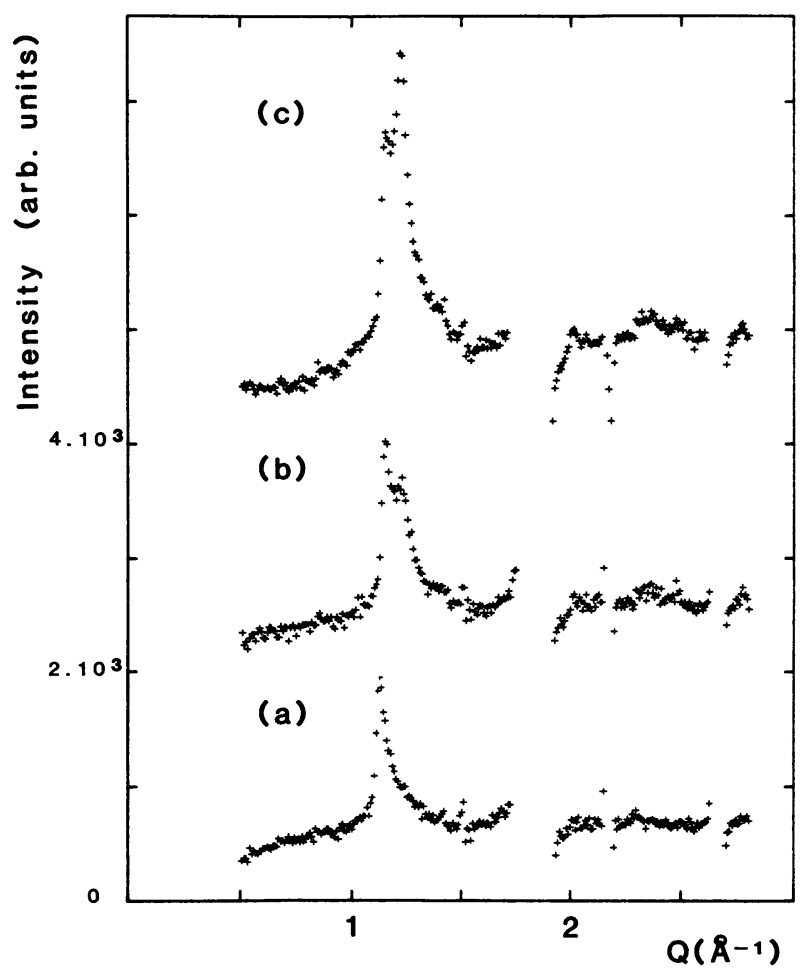

Fig. 8. - Neutron diffraction profiles of cyclohexane films adsorbed on 0.1 density Papyex at $233 \mathrm{~K}$ : (a) : 0.9 layer; (b) : 1.3 layer; (c) : 2 layers.

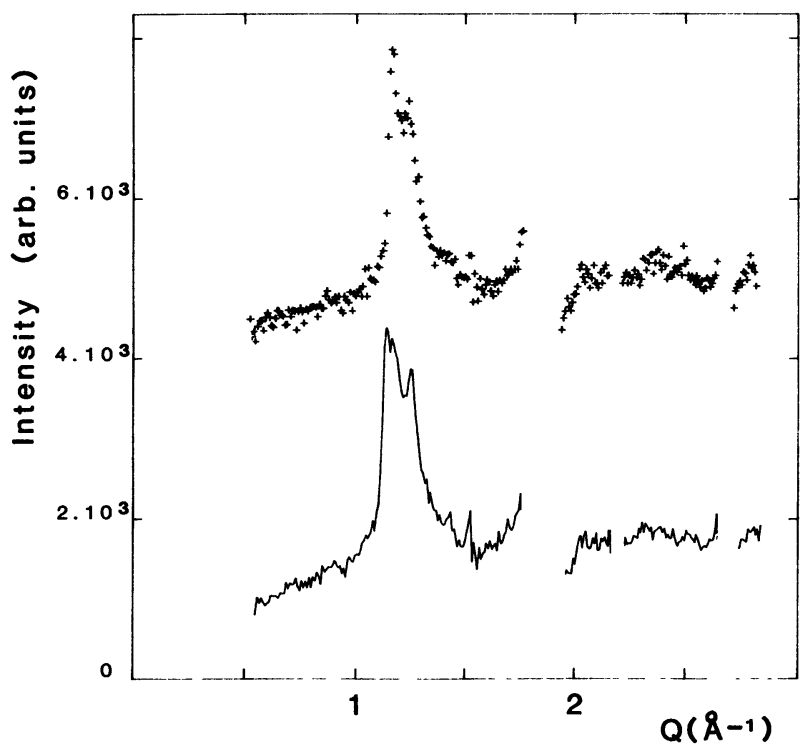

Fig. 9. - Neutron diffraction profile of a 1.3 layer cyclohexane film on 0.1 density Papyex at $233 \mathrm{~K}$. The smooth curve is obtained by summing $0.7 \times(0.9$ layer spectrum $)$ and $0.3 \times(2$ layers spectrum $)$ at the same temperature. 
graphite before reaching the saturating vapour pressure. Figure 8 shows the diffraction patterns of 1.3 and 2 layer films. When two layers are adsorbed (Fig. 8c), six Bragg peaks can be distinguished in the spectrum, very similar to those obtained for a complete monolayer at $77 \mathrm{~K}$ (Fig. 7). It may be assumed to correspond to the same structure with slightly different parameters $\left(a=5.75 \AA, b=6,09 \AA, \gamma=118.15^{\circ}\right)$ due to thermal expansion. In the 1.3 layer pattern, the first two Bragg peaks $\left(Q=1.17\right.$ and $\left.Q=1.26 \AA^{-1}\right)$ already observed for the two layer pattern are also observed at about the same positions, but with reversed relative intensities. Such a pattern can be obtained by a linear combination of 0.9 and 2 layer spectra, as shown in figure 9. This observation implies the coexistence of the hexagonal 0.9 layer phase with a bilayer phase a rectangular structure during the first order transition process of second layer formation. Figure $9 \mathrm{~b}$ has been obtained, assuming that $70 \%$ of the graphite surface is covered with a monolayer of hexagonal structure and $30 \%$ with a bilayer, which corresponds exactly with the 1.3 layer total coverage.

The spectrum presented in figure $10 \mathrm{a}$ is obtained at $233 \mathrm{~K}$ when a cyclohexane volume equivalent to 15 layers is introduced in contact with the sample. Subtraction of the two layer spectrum (Fig. 8c) from figure 10a leads to the pattern of figure 10b on which the Bragg peaks are much more symmetrical, and characteristic of a $3 \mathrm{D}$ phase. This observation is in agreement with thermodynamical results, according to which two layers are adsorbed at $233 \mathrm{~K}$ before reaching the saturating vapour pressure. The Bragg peak positions are those of the face centered cubic structure previously found for the 3D cyclohexane crystal at this temperature $[16,17]$.

Figure 11 shows the scattering profile obtained when cooling the two layer film to $150 \mathrm{~K}$. Typically 3D peaks arise (marked by an arrow in Fig. 11), whereas the relative intensities of the first two Bragg peaks are reversed with respect to the same coverage spectrum at $233 \mathrm{~K}$. These features probably mean that the second adsorbed layer is stable only for temperatures higher than predicted from thermodynamical results $(145 \mathrm{~K})$ [8].

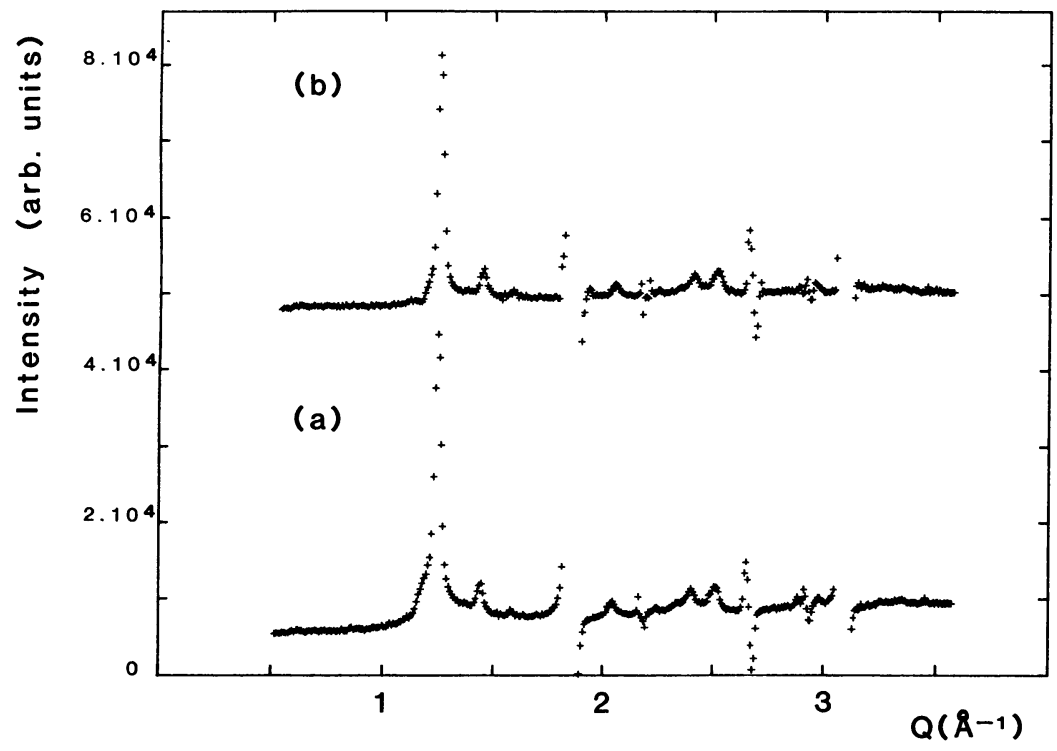

Fig. 10. - Neutron diffraction profile of 3D cyclohexane at $233 \mathrm{~K}:$ (a) spectrum obtained when a cyclohexane amount equivalent to 15 layers is introduced in contact with 0.1 density Papyex ; (b) the same when the two layers spectrum has been subtracted. 


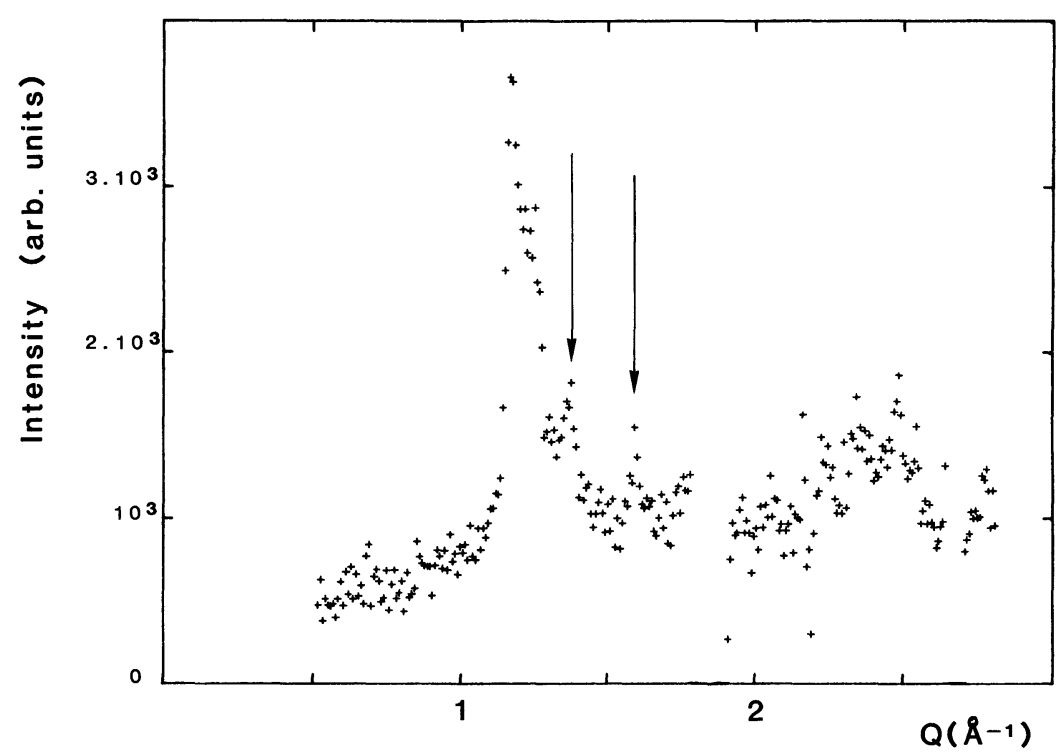

Fig. 11. - Neutron diffraction spectrum of a two layers cyclohexane film adsorbed on 0.1 density Papyex at $150 \mathrm{~K}$. Bragg peaks marked by an arrow are clearly $3 \mathrm{D}$.

In conclusion to this section, it was shown from a neutron diffraction study on 0.1 density Papyex, in agreement with thermodynamical results, that only one cyclohexane layer is adsorbed on graphite at $77 \mathrm{~K}$, while two layers are adsorbed at $233 \mathrm{~K}$ before 3D condensation. The densest structure of the monolayer adsorbed at $77 \mathrm{~K}$ has a centered rectangular unit cell. The same structure is observed when two layers are adsorbed at $233 \mathrm{~K}$. The second layer filling at $233 \mathrm{~K}$ involves a first order transition from one layer with hexagonal structure to a bi-layer with a centered rectangular structure.

3.3 X-RAY SCATTERING STUDY. - In the diffraction pattern obtained with X-rays incident upon a 0.9 layer cyclohexane film adsorbed at $77 \mathrm{~K}$, two Bragg peaks are observed around $Q=1.14 \AA^{-1}$ and $Q=2.36 \AA^{-1}$, which can be assigned to the same hexagonal incommensurate structure as observed in neutron scattering experiments. The intensities of the two observed peaks are in the ratio 100-16, instead of 100-62 as observed in the neutron scattering pattern measured at the same temperature and cyclohexane coverage (Fig. 2). This discrepancy can be explained by the difference in neutron and X-ray scattering cross sections of the $\mathrm{C}_{6} \mathrm{H}_{12}$ atoms. Using the model of Ruland and Tompa with the orientation determined by neutron scattering for the same coverage and temperature for the $\mathrm{C}_{6} \mathrm{H}_{12}$ molecule, the intensities of the Bragg peaks located at $Q=1.14 \AA^{-1}$ and $Q=2.36 \AA^{-1}$ are in the ratio $100 / 13$, in good agreement with the observed values on the X-ray scattering profile. This corroborates the validity of this orientation.

In the following analysis we shall only consider the small angle Bragg peaks $\left(Q<1.4 \AA^{-1}\right)$ and assume that the observed structures are the same as those determined by neutron scattering when the peaks are located at the same wave vectors as in the full neutronscattering profiles. Figure 12 shows a sequence of X-ray diffraction patterns at a fixed coverage of 1 monolayer, and various temperatures. Within the considered wave vector range, only one Bragg peak is observed between 233 and $111 \mathrm{~K}$, whose position varies from $Q=1.14 \AA^{-1}$ to $Q=1.17 \AA^{-1}$ with decreasing temperature. This peak can be assigned to 


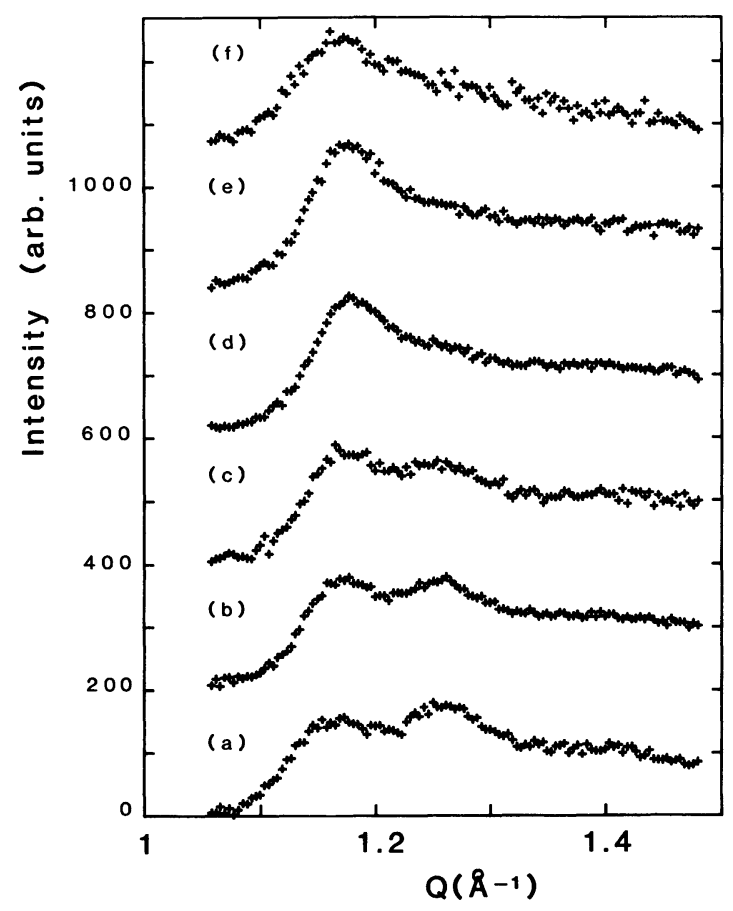

Fig. 12. - X-ray diffraction profile of a one layer cyclohexane film adsorbed on 1.1 density Papyex. Dependence on temperature : (a) : $77 \mathrm{~K}$; (b) : $104 \mathrm{~K}$; (c) : $107 \mathrm{~K}$; (d) : $111 \mathrm{~K}$; (e) : $160 \mathrm{~K}$; (f) : $233 \mathrm{~K}$.

the incommensurate hexagonal phase already determined, with a unit cell parameter continuously decreasing with decreasing temperature, down to a value of $6.25 \AA$ at $111 \mathrm{~K}$. A new Bragg peak $\left(Q=1.26 \AA^{-1}\right)$ arises at $107 \mathrm{~K}$, whose relative intensity with respect to the first peak $\left(Q=1.17 \AA^{-1}\right)$ increases when decreasing temperature. The features observed at $77 \mathrm{~K}$ are those of the centered rectangular solid already elucidated by neutron scattering experiments. Spectra at 107 and $104 \mathrm{~K}$ may be obtained by a linear combination of the hexagonal structure one peak pattern with the rectangular structure two peaks pattern, implying the coexistence of these two structures (Fig. 13).

The main contribution of X-ray scattering experiments to this study is then to enable the determination of the type of transition occurring between the different phases of a solid $\mathrm{C}_{6} \mathrm{H}_{12}$ film adsorbed on graphite in the monolayer range. There is a continuous transition from a $\sqrt{7} \cdot \sqrt{7}$ commensurate to hexagonal incommensurate structure with progressive decrease of the unit cell parameter. The transition from the incommensurate hexagonal phase to the centered rectangular phase is first order, evidenced by the coexistence of the two solids.

\section{Conclusion.}

All the results obtained in the first monolayer range are summarized in the phase diagram proposed in figure 14. The different temperatures and coverages studied either by neutron scattering or by X-ray scattering are reported in the diagram, and enable to locate the 


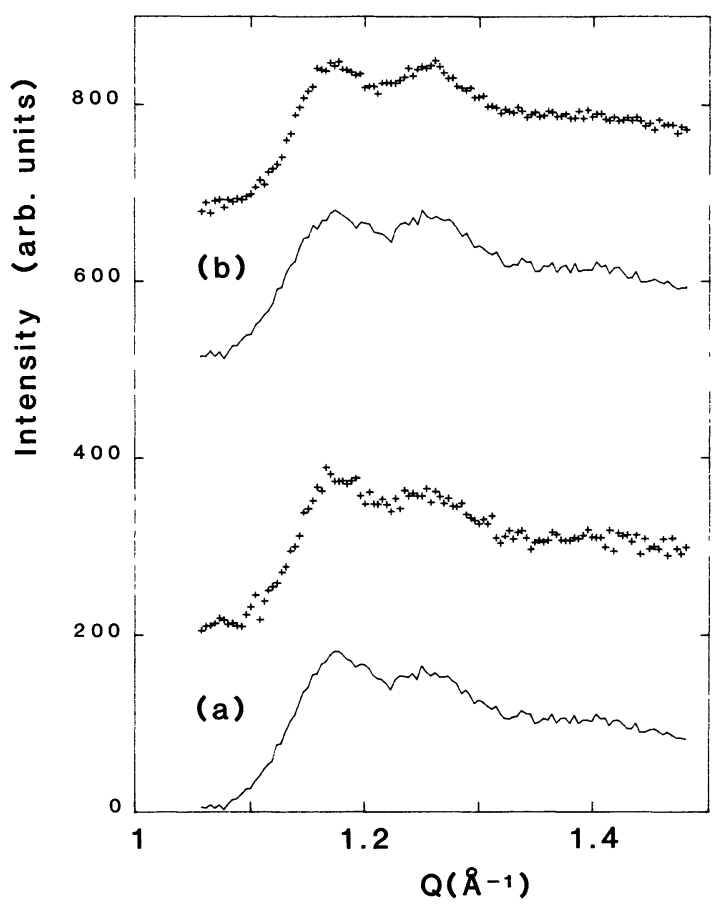

Fig. 13. - X-ray diffraction profiles of one layer cyclohexane film adsorbed on 1.1 density Papyex, (a) $107 \mathrm{~K}$. The smooth curve is obtained by summing the $77 \mathrm{~K}$ spectrum with $0.9 \times(111 \mathrm{~K}$ spectrum $)$; (b) : $104 \mathrm{~K}$. The smooth curve is obtained by summing the $77 \mathrm{~K}$ spectrum with $0.4 \times(111 \mathrm{~K}$ spectrum $)$.

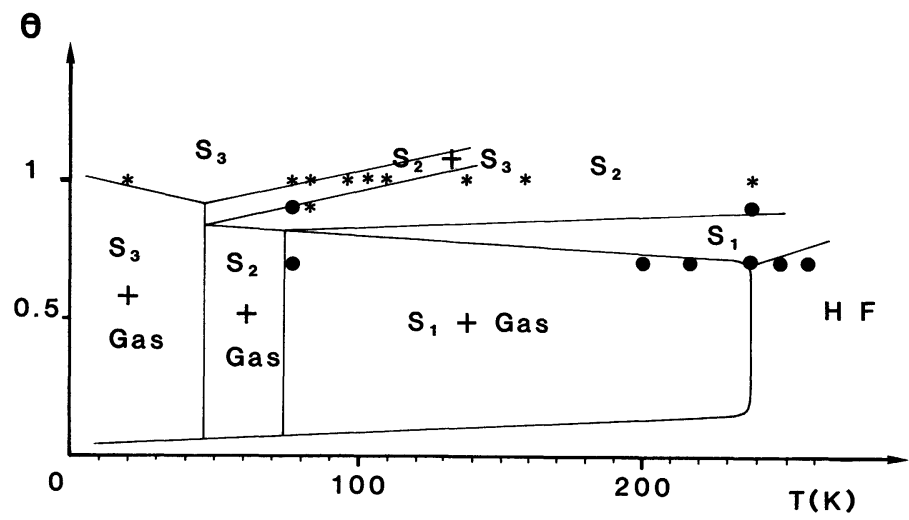

Fig. 14. - Phase diagram for a cyclohexane monolayer on graphite : $\theta$ : fractional coverage ; $S_{1}$ : commensurate $\sqrt{7} \cdot \sqrt{7}$ phase $; S_{2}$ : incommensurate hexagonal phase $; S_{3}$ : centered rectangular phase ; H.F. : hypercritical fluid ; $(\bullet)$ physical conditions for neutron scattering experiments ; $(*)$ physical conditions for X-ray scattering experiments.

boundaries of existence or coexistence domains of the different phases. The three observed solid structures are, in order of increasing density :

- a commensurate hexagonal $\sqrt{7} \cdot \sqrt{7}$ structure $\left(S_{1}\right)$ with unit cell parameter $a=6.51 \AA$; 
- an incommensurate hexagonal structure $\left(S_{2}\right)$ with unit cell parameter continuously varying from 6.51 to $6.25 \AA$;

- a centered rectangular structure with unit cell parameters $a=5.63 \AA, b=6,06 \AA$, $\gamma=117,65^{\circ}$.

The phase transition $S_{1}-S_{2}$ is continuous.

The phase transition $S_{2}-S_{3}$ is first order.

The melting temperature of the $S_{1}$ structure, studied for a 0.7 layer coverage, was estimated to be $240 \mathrm{~K}$.

Moreover, it was shown that only one monolayer is adsorbed at $77 \mathrm{~K}$ before 3D condensation, whereas two layers are adsorbed at $233 \mathrm{~K}$. The rectangular structure $\mathrm{S}_{3}$ is also observed for the 2-layer film at $233 \mathrm{~K}$. The second layer completion occurs according to a first order transition process from a hexagonal monolayer $\left(S_{2}\right)$ to a centered rectangular bilayer $\left(\mathrm{S}_{3}\right)$.

\section{Acknowledgments.}

The authors are grateful to professors X. Duval, C. Marti and A. Thomy for helpful discussions.

\section{References}

[1] Tomy A., Duval X. and Regnier J., Surf. Sci. Rep. 1 (1981) 1.

[2] Suzanne J., Coulomb J. P., Bienfait M., Matecki M., Thomy A., Croset B. and Marti C., Phys. Rev. Lett. 41 (1978) 760 ;

Coulomb J. P., Suzanne J., Bienfait M., Matecki M., Tomy A., Croset B. and Marti C., J. Phys. France 41 (1980) 1155.

[3] Marti C., Ceva T., Croset B., De Beauvais C. and Thomy A., J. Phys. France 47 (1986) 1517.

[4] Kim H. K., Feng Y. P., Zhang Q. M. and Chan M. H. W., Phys. Rev. B 37 (1988) 3511.

[5] Smith R. N., Pierce C. and Cordes H., J. Am. Chem. Soc. 72 (1950) 5595.

[6] Pierce C. and Ewing B., J. Phys. Chem. 71 (1967) 3408.

[7] Khatir Y., Coulon M. and Bonnetain L., J. Chim. Phys. 75 (1978) 796.

[8] Delachaume J. C., Thesis, Grenoble (1985).

[9] Marti C., Croset B., Thorel P. and Coulomb J. P., Surf. Sci. 65 (1977) 532.

[10] Coulomb J. P., Thesis, Marseille (1981).

[11] Croset B., Thesis, Marseille (1983).

[12] Ceva T., Goldmann M. and Marti C., J. Phys. France 47 (1986) 1527.

[13] Bockel C., Coulomb J. P. and Dupont-Pavlovsky N., Surf. Sci. 116 (1982) 369.

[14] Jensen E. R., Noyce D. S., Sederholm C. H. and Berlin A. J., J. Am. Chem. Soc. 82 (1960) 1256.

[15] Farman H., Dore J. C., Bellisent-Funel M. C. and Montague D. G., Mol. Phys. 61 (1987) 583.

[16] Kahn R., Fourme R., André D. and Renaud M., C.R. Acad. Sci. 271B (1970) 1078.

[17] Kahn R., Fourme R., André D. and Renaud M., Acta Crystallogr. B 29 (1973) 131.

[18] Ruland W. and Tompa H., Acta Crystallogr. A 24 (1968) 93.

[19] Ruland W. and Tompa H., J. Appl. Crystallogr. 5 (1972) 225.

[20] Coulomb J. P., Madih K., Croset B. and Lauter J., Phys. Rev. Lett. 54 (1985) 1536.

[21] Monkenbusck M. and Stockmeyer R., Ber. Bunsenges. Phys. Chem. 84 (1980) 408.

[22] Gameson I. and Rayment T., Chem. Phys. Lett. 123 (1986) 150.

[23] Bardi U., Magnanelli S. and Rovida G., Langmuir 3 (1987) 159. 